\title{
Psychosocial impairments among adults with epilepsy in a neurology clinic in Nigeria
}

\author{
${ }^{*}$ Tunde-Ayinmode MF. ${ }^{1,2}$, Abiodun OA. ${ }^{1,2}$, Ajiboye PO. ${ }^{1,2}$, Buhari OIN. ${ }^{1,2}$
}

\begin{abstract}
Objective: Psychosocial problems unattended to may compromise adequate control of seizures and elevate the risk of psychopathology. We assessed for psychosocial impairments and associated psychopathology in patients with epilepsy, with the hope that findings will help initiate formal psychosocial care for patients attending the neurology clinic.
\end{abstract}

Methods: Consecutive patients with epilepsy seen at the neurology clinic that met the inclusion criteria and gave consent were interviewed in a 2 stage procedure. In the first stage patients were assessed with a semi-structured questionnaire containing psychosocial variables while probable psychiatric morbidity was assessed with General Health Questionnaire (GHQ-12). In the second stage psychiatric diagnoses were assessed with Schedule for Clinical Assessment in Neuropsychiatry (SCAN).

Results: Many of the patients reported difficulties in at least one or more of the psychosocial domains assessed; areas of difficulty included: physical activity (52.4\%), occupational activity (46.8\%); finances (41.3\%); stigma (33.3\%); inadequate social support by relatives $(31.7 \%)$, and perceived inadequate general adjustment (34.9\%). Psychosocial factors significantly associated with increased rate of psychopathology included: being a woman, having low education; financial difficulties and limitations in physical activities while significant clinical factors included: having frequent fits and partial epilepsy. Multiple logistic regression analyses indicated that being a woman and having partial seizures were the most important predictors of psychopathology among the patients.

Conclusion: This study has provided evidence of the need to introduce routine psychosocial care in our neurology clinic which hitherto did not carry out structured routine assessment of psychosocial problems in order to reduce risk of psychopathology.

Keywords: Psychosocial impairments, adults, epilepsy, neurology clinic, Nigeria

*Corresponding author: Tunde-Ayinmode, Email: mosunmolaflorence@yahoo.com

${ }^{1}$ Department of Behavioural Science, College of Health Sciences, University of Ilorin, Ilorin, Nigeria.

${ }^{2}$ Department of Behavioural Science, University of Ilorin Teaching Hospital, Ilorin, Nigeria.

Research Journal of Health Sciences subscribed to terms and conditions of Open Access publication. Articles are distributed under the terms of Creative Commons Licence (CC BY-NC-ND 4.0). (http://creativecommons.org/licences/by-nc-nd/4.0).

http://dx.doi.org/10.4314/rejhs.v5i1.6 


\title{
Troubles psychosociaux chez les adultes atteints d'épilepsie dans une clinique de neurologie au Nigeria
}

\author{
*Tunde-Ayinmode MF. ${ }^{1,2}$, Abiodun OA. ${ }^{1,2}$, Ajiboye PO. ${ }^{1,2}$, Buhari OIN. ${ }^{1,2}$
}

\begin{abstract}
Resume
Objectif: Les problèmes psychosociaux sans surveillance peuvent compromettre le contrôle adéquat des crises et élever le risque de psychopathologie. Nous avons évalué les déficiences psychosociales et la psychopathologie associée chez les patients atteints d'épilepsie, avec l'espoir que les résultats aideront à initier des soins psychosociaux formels pour les patients qui fréquentent la clinique de neurologie.
\end{abstract}

Méthodes: Les patientes consécutives atteintes d'épilepsie à la clinique de neurologie qui satisfaisaient aux critères d'inclusion et ont donné leur consentement ont été interrogées dans le cadre d'une procédure en 2 étapes. Dans la première étape, les patients ont été évalués à l'aide d'un questionnaire semi-structuré contenant des variables psychosociales, tandis que la morbidité psychiatrique probable a été évaluée à l'aide du questionnaire GHQ-12. Dans la deuxième étape, les diagnostics psychiatriques ont été évalués à l'aide du Tableau d'évaluation clinique en neuropsychiatrie (SCAN).

Résultats: Beaucoup de patients ont signalé des difficultés dans au moins un ou plusieurs des domaines psychosociaux évalués; Les domaines de difficulté étaient les suivants: activité physique (52,4\%), activité professionnelle (46,8\%); Finances publiques (41,3\%); Stigmatisation $(33,3 \%)$; Un soutien social inadéquat de la part des parents $(31,7 \%)$ et un ajustement général inadéquat $(34,9 \%)$. Les facteurs psychosociaux associés de façon significative à un taux accru de psychopathologie étaient: être une femme, avoir un faible niveau d'éducation; Les difficultés financières et les limitations des activités physiques, alors que les facteurs cliniques importants incluaient: des crises fréquentes et une épilepsie partielle. Des analyses de régression logistique multiples ont montré que le fait d'être une femme et d'avoir des crises partielles étaient les prédicteurs les plus importants de la psychopathologie chez les patients.

Conclusion: Cette étude a démontré la nécessité d'introduire des soins psychosociaux systématiques dans notre clinique de neurologie qui n'a pas effectué jusqu'à présent d'évaluation routinière structurée des problèmes psychosociaux afin de réduire le risque de psychopathologie.

Mots clés: Troubles psychosociaux, adultes, épilepsie, clinique de neurologie, Nigeria

\footnotetext{
*Auteur correspondant: Tunde-Ayinmode, Email: mosunmolaflorence@yahoo.com

'Department of Behavioural Science, College of Health Sciences, University of Ilorin, Ilorin, Nigeria.

${ }^{2}$ Department of Behavioural Science, University of Ilorin Teaching Hospital, Ilorin, Nigeria.
} 


\section{INTRODUCTION}

It has been observed that people with epilepsy have more psychosocial problems than the normal population. This suggests that psychosocial maladjustment to the disorder may be a frequent phenomenon. The complex biopsychosocial dimensions of epilepsy, its unpredictable nature and course, and issues related to its treatment are factors that influence the psychosocial handicaps it engenders (1-5). Psychosocial adjustment is how well the affected patient responds to the various challenges posed by epilepsy. Few examples of the common psychosocial adjustment problems reported in epilepsy include: stigmatization, educational deprivations and underachievement, vocational difficulties like unemployment and underemployment, difficulty getting married, financial problems, inconveniences of treatment and follow-ups; driving restrictions; intrusiveness in valued activities and psychological distress of various kinds like fears, anxieties, anger or sadness and loss of previous future plans (1-7).

Persistence of psychosocial problems may become too distressing for the patient sometimes more than the seizures themselves and when adjustment is unsuccessful other complications may emerge such as mental ill health, difficulties with seizures control and reduction in quality of life $(4,8)$. It is therefore important to study and understand psychosocial dimensions associated with epilepsy $(2,3,5)$.

What evokes psychosocial problems in patients with seizure disorder vary. Some of these factors include the degree of visibility of the emerging symptoms and signs, frequency of occurrence, complications that occur and the degree of unpredictability of the seizures (1-3). Seizure related consequences of psychosocial morbidity include poor compliance with medications, poor self-management attitudes and behaviors which result in more frequent fits and poorer outcome $(2-4,9)$.

Characteristics of the patients that help to minimize or abolish the consequences of these psychosocial problems consist of the coping resources available to the patients and these include: economic factors (e.g. gainful employment), family factors (e.g. stable marriage, being a parent, extended family support) and social factors such as network of friends among others $(4,9-12)$.

Stigma, vocational and educational problems are three psychosocial issues that require special emphasis because they are common and are known to elevate the risk of psychopathology as well as that of the occurrence of the other complications of psychosocial dysfunctions described above (3, 13-21). Stigma is a psychosocial problem that occurs in patients with epilepsy globally and prevalence rates may be more than $50 \%$. Vocational problems vary from outright unemployment to underemployment, underperformance, absenteeism or negative employer attitude and exclusion from leadership roles (17). Examples of complications that may occur from these vocational problems are financial difficulties and increased risk of psychopathology. Financial difficulties in patients with epilepsy can also occur from the cost of buying medications and carrying out investigations. Educational problems may start in childhood from school absenteeism and effects of antiepileptic drugs which could lead to the experience of underachievement or failure in school or even drop out. Education is an important coping resource (19). Its poor status could thus contribute to inadequate control, reduced quality of life and maladjustment $(19,20)$.

It has been observed that there is substantial unmet psychosocial assessment and management needs in epilepsy in both developing and advanced countries (22). A number of studies in Nigeria have confirmed this view (14-16) but studies required to guide intervention programs are scarce in the country. Effective, well functioning and successful intervention programs require knowledge of psychosocial adjustment of patients in individual localities and practice settings (22).

In this study we assessed the psychosocial problems of patients with epilepsy and their association with psychopathology, with the hope that the findings will help in the development of psychosocial care for patients with epilepsy.

\section{MATERIALS AND METHODS}

This paper is derived from a larger study conducted in the Neurology clinic of university of Ilorin teaching hospital, Ilorin, Nigeria. Ilorin, the capital of Kwara state is a cosmopolitan city in which the Yoruba language and culture along with Islamic tradition are prominent. Kwara state is located in the North-central geopolitical region of the country and has a population of about 2.3 million (23). University of Ilorin teaching hospital is the main referral centre for the host state and parts of 5 other adjoining states. The 
neurology clinic is run by 2 consultant neurologists and a complement of resident (trainee) physicians at various levels of training. The clinic receives patients from the family medicine department (the primary care unit of the hospital), the pediatric, behavioral sciences and internal medicine departments and from other centers outside the hospital. The clinic runs outpatient services once a week.

\section{Sampling method:}

The main study was a two-stage investigation in which all consecutive attendees to the clinic (both new and follow-up cases) that had been diagnosed as having epilepsy by the consultant neurologists supervising the clinic were approached to participate in the study. The diagnoses were on the basis of symptomatology and EEG. Those who gave informed consent were recruited over the one year period that the study in the neurology clinic lasted.

\section{Instruments and Data collection:}

Data collection was done by the consultant psychiatrists assisted by research assistants. At the start of the clinic, the case notes of each patient with epilepsy was identified and separated. The research assistants sought the patients out and asked for their consent to participate after appropriate information about the study had been given. When consent was obtained the case note was marked to indicate recruitment and also avoid double sampling. The questionnaires were then administered to the patients.

In the present study, participants were interviewed with a pro-forma questionnaire designed by the authors, which included sociodemographic variables like age, gender, etc and psychosocial factors that are known from literature to impact on epilepsy like: birth and childhood characteristics, family and interpersonal adjustment including stigma, vocational adjustment, physical or domestic work adjustment, financial adjustment and overall adjustment. Clinical data such as the nature of epilepsy and other relevant information were extracted from the case notes. Also in the first stage, the participants were screened for current psychiatric morbidity using the 12 -item general health questionnaire (GHQ-12) (24). The general health questionnaire (GHQ) is a well known screening instrument for psychological or psychiatric disorders that has been used in many countries of the world including Nigeria (24). It enquires about recent changes in mental wellbeing. In Nigeria, GHQ-12 has been validated in non-psychiatric populations of a general hospital and in a community sample (25). The optimum cut-off point (i.e. score which gives optimum sensitivity and specificity and minimum misclassification rate) was a score of three (25).

The patients who scored 3 and above on GHQ-12 and 1 out of every 5 (20\%) of those scoring less than 3 (GHQ negative or non-cases) were interviewed in the second stage. The percentage of GHQ negative patients included in the second stage was predetermined based on the misclassification rate of the instrument in the study setting (25). In recruiting this group, the first GHQ-12 negative patient was chosen by balloting (simple random technique) and then every $5^{\text {th }}$ patient afterward. The research assistants in the first stage had a list of all patients seen. The GHQ negative patients were recruited to minimize type II error, (i.e. to reduce the number of false negative individuals).

In the second stage, the patients were assessed for psychiatric disorders with the Schedule for Clinical Assessment in Neuropsychiatry (SCAN) (26). SCAN is a WHO diagnostic instrument for clinicians trained in its use for the assessment and classification of psychopathology and behaviors associated with the major psychiatric disorders of adult life.

The SCAN was applied by three trained consultant psychiatrists. These consultants were unaware of the participants' scores on GHQ-12. There was good inter-rater reliability among the three consultant psychiatrists; Kappa was $89 \%$. Diagnoses of psychiatric disorders were based on ICD-10 criteria. Ethical approval for the study was obtained from the hospital ethical committee.

\section{Data analysis}

Data analysis was done using Statistical Package for Social Sciences (SPSS) version 16.0 for Windows. Simple frequency tables and cross tabulations were generated to detect variable distribution trends and associations while ChiSquare and Fishers exact tests were used to test for significant differences. $P$ value less than 0.05 was set as the level for statistically significant difference.

Risk factors that were significantly associated with the presence of psychiatric diagnosis were then entered as predictor 
variables into stepwise multiple regression analysis with backward elimination in SPSS. All the variables that were significant at the beginning of the process were entered into the full model equation. Multicollinearity check was carried out. Variables were eliminated on the basis of Score statistics, Walds statistics and maximum likelihood ratio until no more could be removed. This method calculated log odds from regression coefficients for each independent variable in the equation and generated the best fitting model after adjusting for the others.

\section{RESULTS}

\section{Socio-demographic characteristics:}

Sixty-nine patients were approached to participate in the study but only 63 adult patients gave informed consent and participated fully in the study over a one year period. The mean age was $34.43(\mathrm{SD}=13.79)$. There were 36 males $(57.1 \%)$ and 27 females $(42.9 \%)$. Patients who were less than 40 years were in the majority $(71.4 \%)$. Those with primary school or less in educational status were $28(44.4 \%)$. Twenty-nine (46.1\%) patients were married while 34 (54\%) were not married. Almost 6 out of every 10 $(57.1 \%)$ of the participants were unemployed (Table 1).

\section{Clinical characteristics:}

The majority 39 (61.9\%) had generalized tonic-clonic epileptic seizures. Others included complex partial seizures $7(11.1 \%)$, partial seizure with secondary generalization $6(9.5 \%)$, absence seizure $1(1.6 \%)$, simple partial $1(1.6 \%)$ and in $9(14.3 \%)$ patients seizures were not classified. In $30(47.6 \%)$ participants seizure disorders were less than 5 years in duration while it had lasted for 5 or more years in $33(52.4 \%)$ patients. Majority of the patients had seizure frequency of less than one per month (32 or $50.8 \%$ ) while $22(34.9 \%)$ patients had more than one seizure per month.

\section{Analysis of psychosocial characteristics:}

The overall prevalence of current diagnosable psychiatric disorders by SCAN was $28.6 \%$. There were 21 patients $(33.3 \%)$ who reported experiencing illness related stigma. Epilepsy-related psychosocial problems were reported in the following areas: physical activities (52.4\%), occupational activities $(46.8 \%)$, finance $(41.3 \%)$, perceived inadequate social support $(31.7 \%)$ and inadequate overall adjustment to the disorder (34.9\%), Table 2 .

An assessment of the relationship between various variables revealed the following: Patients who reported perceived illness related stigma had significant difficulties in the areas of finance $\left(\chi^{2}=15.85 ; \mathrm{P}=0.000\right)$, physical activity $\left(\chi^{2}=8.23\right.$; $\mathrm{P}=0.016)$ and occupational activities $\left(\chi^{2}=7.60\right.$; $\mathrm{P}=0.006)$. Those with financial difficulties were significantly more likely to report problems in the domains of occupation $\left(\chi^{2}=12.08 ; \mathrm{P}=0.002\right)$, and physical activities $\left(\chi^{2}=7.60 ; P=0.006\right)$. The patients with partial seizure were more likely than those with generalized seizures to report problems in the area of finance $\left(\chi^{2}=12.02\right.$; $\mathrm{P}=0.002)$. Furthermore, subjects limited in the area of physical activities were also likely to be limited in the area of occupation $\left(\chi^{2}=42.12\right.$; $\mathrm{P}=0.000)$ while those who reported experiencing adequate social support were more likely to be reporting adequate levels of overall adjustment to epilepsy $\left(\chi^{2}=11.66 ; \mathrm{P}=0.001\right)$.

\section{Univariate analysis of associated factors of psychiatric morbidity:}

In the univariate analysis many clinical and psychosocial variables were assessed for their relationships with the presence or absence of psychiatric morbidity. The odds of having a psychiatric diagnosis was 4 times larger for those older than 40 years than those below 40 years $(\mathrm{OR}=0.25, \mathrm{CI}=0.06-0.94, \mathrm{p}=0$. 038); 5.9 times larger for women than men $(\mathrm{OR}=0.17, \mathrm{CI}=0.04$ $0.67, p=0.007) ; 7.7$ times more in those with abnormal EEG results than those with normal results. $(\mathrm{OR}=0.13, \mathrm{CI}=0.01-1.06, \mathrm{p}=0.042) ; 6.1$ times more in partial than in generalized epilepsy $(\mathrm{OR}=6.10, \mathrm{CI}=1.34-29.36, \mathrm{p}=0.012) ; 4.8$ times more in physical activity limited patients than those not so limited $(\mathrm{OR}=4.79, \mathrm{CI}=1.2-20.68$, $\mathrm{p}=0.023) ; 6.8$ times more in occupational activity limited patients than those without limitation $(\mathrm{OR}=6.77, \mathrm{CI}=1.66-29.00, \mathrm{p}=0.004)$ and 4.4 times more in those with illness related financial problems than those without such problems $(\mathrm{OR}=4.43, \mathrm{CI}=1.21-16.87, \mathrm{p}=0.021)($ Table 3$)$.

\section{Multivariate analysis of associated factors of psychiatric morbidity:}

Every variable identified in the univariate analysis as significantly associated factor was entered into the full model equation in logistic regression analysis.

At the end of all possible steps and iterations two variables, gender, (being a woman) (with Exp $\mathrm{B}=0.07, \mathrm{CI}=0.01-0.52, \mathrm{p}=0.01)$ and type of seizure (having partial epilepsy) (with Exp $\mathrm{B}=$ 7.56, $\mathrm{CI}=1.24-46.56, \mathrm{p}=0.03$ ) remained 
significantly associated with the presence of psychiatric diagnoses (the others having been eliminated). The result suggests that the odd of women having psychopathology was 2.7 times larger than for men while that of patients with partial seizure was 2 times larger than those with generalized epilepsy. These independent variables (being a woman and having partial seizure) provided the best fitting equation for the maximum likelihood ratio and therefore had the strongest influence on the outcome (psychopathology). Thus, they are the best predictors of psychopathology in the study population (Table 4).

\section{Analysis of relationship between psychosocial problems and average GHQ score}

The GHQ score ranged from 0 - 11, mean GHQ score was 1.49 (SD=2.31). Spearman rho correlation coefficient between GHQ and SCAN diagnosis was $(-0.712 ; \mathrm{P}=0.000)$.

Table 5: Shows a trend in which the average GHQ score increases with increasing number of psychosocial problems in the patients (figure 1). There was statistically significant increase in total GHQ scores with increasing number of psychosocial problems $\left(\chi^{2}=22.5 ;\right.$ df $=6$; $\mathrm{P}=0.000)$. The psychosocial problems included in the analysis were: Stigma, limitations in physical activities, limitation in occupational activities, financial difficulties, and problems with family support, problems with overall adjustment, problems with education, problems with employment and problems with marriage.

\section{DISCUSSION}

\section{Psychosocial problems of epilepsy patients}

Psychosocial difficulties that many patients with epilepsy bring to the clinic may not be identified because they do not mention them and doctors do not inquire about them. This type of situation is likely to occur in the busy outpatient clinics that characterize many developing countries including Nigeria.

One of the most common social problems a patient with epilepsy may experience is stigmatization and this was observed to be prevalent (one-third) in our study population, as was observed in previous studies $(13,27)$. Stigma in epilepsy has been extensively studied (13, 21, 27 ) and is known to have several complications (13-16). In the present study, stigma was associated with impairment in other psychosocial domains like finance and physical and occupational activities, thus supporting previous studies that have found stigma to be a risk factor for additional psychosocial problems $(7,21)$. Intervention programs at the clinic would need to include preventing and minimizing the experience of stigma and its effects.

About a fifth of our patients with epilepsy had no formal education. Epilepsy is known to disadvantage sufferers in education attainment (5). In addition, lack of education reduces their chances of successful counseling, health education and self-management; and ability to cope with problems of stigma and drug compliance.

Close to two-thirds of our patients were not gainfully employed suggesting existing problems with vocation as previous studies have reported $(5,17,28)$. Also related, about half of our patient had disease linked financial difficulties which was associated with psychosocial impairments in other domain like physical activity, occupation and social interactions. Patients with epilepsy are known to report lots of disease related financial difficulties $(5,7,20)$. These intertwined factors may make epilepsy more difficult to control and need to be tackled at the clinic level through adequate psychosocial assessment and psychosocial care.

The positive role of perceived social support in coping with chronic physical disorders like epilepsy has been well documented $(2,3)$. Our patients who reported adequate social support had better overall adjustment to epilepsy. This suggests that information about social support should be sought at the clinic level and adequate social support as a coping resource should be promoted. Social support like other factors such as gainful employment and stable marriage are known coping resources that may help minimize stress $(4,9,10)$.

Psychosocial difficulties negatively affect the adequate management of patients with epilepsy and this need to be recognized by their caregivers. It has been observed that patients with psychosocial problems are more likely to have difficulties controlling their seizures (2-4). In this study, evidence was provided that supports this view as there was a significant association between increasing frequency of seizures (suggesting suboptimal seizure control) and presence of financial, physical and occupational problems. This suggests that attention to solving patients' psychosocial problems could be one of the non-drug strategies to help reduce the frequency of seizures in the study population

\section{Psychosocial problems and psychopathology}

Psychosocial problems are not only distressing to 
the patients but are also known to increase their vulnerability to psychopathology, thereby causing more distress $(5,29)$.

The present study was able to identify some clinical and social factors considered as psychopathology risk factors because they were associated with increased rates of psychiatric disorders. Female gender, lower educational status, having partial seizures, impairments in physical and occupational activities and finance were identified as risk factors for psychopathology. In addition, being a woman and having partial epilepsy predicted higher prevalence of psychopathology. These findings have support from some previous studies (30-33).

The higher rate of psychopathology among women as seen in our cohort is in agreement with a previous study (34) in which being a female was identified as a risk factor for depression and anxiety in patients with epilepsy. Women have also been reported to be more prone to psychosocial problems than men and there are certain gender-specific issues in epilepsy that appear to put women at greater risk of psychopathology (34). Some of these factors include higher rates in women than men of low education, unemployment, divorce, difficulty getting married, stigmatization and other socioeconomic difficulties especially in developing countries $(19,30-32)$. In addition, there are menstrual cycle related seizure vulnerability risks and treatment related reproductive risks that women have to face.

It is however important to state that there are studies which contradict the fact that women with epilepsy may have an increased risk of psychopathology compared to men. Some studies have reported male gender as being a risk factor for psychopathology while others have not found any gender difference in psychopathology, suggesting that gender may not be a risk factor (35).

The fact that increased rate of psychopathology is associated with partial epilepsy compared with generalized epilepsy was also supported by our study. These rates differ among the various subgroups of partial epilepsy (e.g. temporal lobe, extra temporal lobes, lesional, non-lesional). The neurobiological bases of these variations remain largely speculative. It has been suggested that the diffuseness of the pathology, the degree of interruption of neuronal connections at the site of the lesion, disruption of frontolimbic pathways and functional impairment may determine frequency of occurrence of psychopathology in the different types of epilepsy (36).

In our study, we found that increasing number of psychosocial problems resulted in increase in the average GHQ scores of the patients. This finding suggests that the more the number of psychosocial problems a patient with epilepsy has, the more likely the probability of occurrence of psychopathology. Patients with epilepsy with multiple psychosocial problems may thus represent a sub-population in need of special care.

\section{Collaboration between neurologists and psychiatrists}

In this study we have provided evidence that our patients with epilepsy not only have psychosocial problems but these were associated with psychopathology. More important is the fact that these problems were undetected and therefore unmanaged, with probable consequences on disease control and quality of life. There is therefore a need for formal collaboration between the Neurologists and Psychiatrists to improve care. The Neurologists need to address known psychosocialmanagement knowledge and attitude gap $(37,38)$ while the Psychiatrists should establish formal consultation-liaison coverage of the neurology clinic.

\section{Limitations of Study}

Although the present study was conducted over a period of one year, the relatively small sample size is a limitation of study. Further studies will need to address why relatively small number of adult patients with epilepsy attend the neurology clinic, with a view to improving attendance.

Some of the patients might also have responded in a socially desirable manner to some of the items on the psychosocial aspect of epilepsy (a common problem with questionnaires).

\section{CONCLUSION}

On the whole, this study provided evidence that not only did our patients with epilepsy experience psychosocial difficulties but that they had associated psychiatric complications.

These findings suggest the need for a comprehensive psychosocial care program in our neurology clinic. In view of the problems related to inadequate social support and finances, the involvement of the family should be an essential 
aspect of such a program. As a result of the problems of stigma, poor education and employment such a program must also involve public enlightenment through the mass media and the sensitization of policy makers.

Conflict of interest: The authors declare no conflict of interest.

\section{REFERENCES}

1. Baker GA. The Psychosocial Burden of Epilepsy. Epilepsia 2002; 43(Suppl. 6):26-30.

2. Pais-Ribeiro J, Meneses RF. Positive psychosocial variables and outcome variables in persons with epilepsy. In: Mintaze Kerem Gunel eds. Management of Epilepsy - Research, Results and Treatment. CCBY-NC-SA 3.0 license, 2011; 171-194.

3. Lau VWY, Lee TMC, Ng PKK, Wong VCN. Psychosocial Adjustment of People with Epilepsy in Hong Kong. Epilepsia 2001; 42 (9): 1169-1175.

4. Lua PL, Neni WS, Samira TN. Coping with Epilepsy: How Do They Influence HealthRelated Quality of Life (Hrqol)? The Inter J Psychosocial Rehab 2012; 16(2) 114-126.

5. Mula M, Sander JW. Psychosocial aspects of epilepsy: A wider approach. BJPsych 2016; 2: 270-274. doi: 10.1192/bjpo.bp.115.002345

6. Riasi H, Rajabpour Sanati A, Ghaemi K. The stigma of epilepsy and its effects on marital status. Springerplus 2014;3:762.

7. Kobau R, Cui W, Kadima N, Zack MM, Sajatovic M, Kaiboriboon K, Jobst B. Tracking Psychosocial Health in Adults with Epilepsy-Estimates from the 2010 National Health Interview Survey. Epilepsy Behav 2014 Dec; 41: 66-73

8. Stefanello S, Marín-Léon L, Fernandes PT, Li LM, Botega NJ. Depression and anxiety in a community sample with epilepsy in Brazil. Arq. Neuropsiquiatr. 2011; 69: 2b.

9. Poochikian-Sarkissian S, Sidani S, Wennberg R, Devins G. Psychological impact of illness intrusiveness in epilepsy - Comparison of treatments. Psychol Health Med 2008; 13(2): 129-145.

10. de Ridder R, Geenen R, Kuijer H, van Middendorp D. Psychological adjustment to chronic disease. Lancet 2008; 372: 246255.

11. Westerhuis W, Zijlmans M, Fischer K, van Andel $\mathrm{J}$, Leijten FSS. Coping style and quality of life in patients with epilepsy: A cross-sectional study. J Neurol 2011; 258:37-43

12. International League Against Epilepsy (ILAE). Coping with Epilepsy. Epilepsia, 2003 44(Suppl.
6):43-44; Blackwell Publishing, Inc.

13. Jacoby A, Austin JK. Social stigma for adults and children with epilepsy. Epilepsia 2007; 48 (Suppl 9): 6-9.

14. Sanya EO, Salami TA, Goodman OO, Buhari OI, Araoye MO. Perception and attitude to epilepsy among teachers in primary, secondary and tertiary educational institutions in middle belt Nigeria. Trop Doct 2005; 35 (3): 153-6.

15. Akinsulore A, Adewuya A. Psychosocial aspects of epilepsy in Nigeria: a review. Afr J Psychiatry 2010 Nov; 13(5):351-6.

16. Nuhu FT, Fawole JO, Babalola OJ, Ayilara OO, Sulaiman ZT. Social consequences of epilepsy: A study of 231 Nigerian patients. Ann Afr Med 2010; 9 (3): 170-175.

17. Jacoby A, Gorry J, Baker GA. Employers' attitudes to employment of people with epilepsy: still the same old story? Epilepsia. 2005; 46 (12): 1978-1987.

18. Sachin S, Padma MV, Bhatia R, Prasad K, Gureshkumar C, Tripathi M. Psychosocial impact of epilepsy in women of childbearing age in India. Epileptic Disord. 2008; 10: 282-289.

19. Taylor J, Jacoby A, Baker GA, Marson AG, Ring A, Whitehead M. Factors predictive of resilience and vulnerability in new-onset epilepsy. Epilepsia 2011; 52 (3): 610-618.

20. Diop AG, de Boer HM, Mandlhate C, Prilipko L, Meinardi $H$. The global campaign against epilepsy in Africa. Acta Trop 2003; 87: 149-159.

21. Nehra A, Singla S, Bajpai S, Malviya S, Padma V, Tripathi M. Inverse relationship between stigma and quality of life in India: Is epilepsy a disabling neurological condition? Epilepsy Behav 2014; 39:116-125.

22. Mittan RJ. Psychosocial treatment programs in epilepsy: A review. Epilepsy Behav 2009; 16 (3): 371-380.

23. National Population Commission. 2006 Nigeria Census. NPC of Nigeria 2009.

24. Goldberg DP, Gater R, Sartorious N, Ustun TB, Piccinelli M, Gureje O, et al. The validity of 2 versions of the GHQ in the WHO study of mental illness in general health care. Psychol Med 1997; 27: 191-197.

25. Abiodun OA. A study of mental morbidity among primary care patients in Nigeria. Compr Psychiatry 1993; 34 (1): 10-13.

26. World Health Organisation. Schedules for Clinical Assessment in Neuropsychiatry (SCAN) Version 2.1. WHO, Division of Mental Health, Geneva; 1998.

27. Scott RA, Lhatoo SD, Sander JWAS. Epilepsy in developing countries: where do we go from here? Bull World Health Organ 2001; 79: 344-351. 
28. Najam-us Sahar. Assessment of Psychological Distress in Epilepsy: Perspective from Pakistan. Epilepsy Research Treatment 2012; Article ID 171725, doi:10.1155/2012/171725

29. Coenan M, Cobello M, Umlauf S, Ayuso-Mateos JL, Anczewska M, Tourunen J, et al. Psychosocial difficulties from the perspective of persons with neuropsychiatric disorders. Disabil Rehabil 2015; 18: 1-12.

30. Pennell PB, Thompson P. Gender-specific psychosocial impact of living with epilepsy. Epilepsy Behav. 2009; 15 (Suppl 1): S20-25.

31. Luef G. Female issues in epilepsy: A critical review. Epilepsy Behav. 2009; 15: 78-82.

32. Birbeck GL, Chomba E, Atadzhanov M, Mbewe E, Haworth A. Women's Experiences Living with Epilepsy in Zambia. Am J Trop Med Hyg 2008; 79 (2): 168-172.

33. Trimble MR, Sander JW. The psychiatric comorbidity of epilepsy. Acta Neurol Scand 2004; 110: 207-220.

34. Kimiskidis VK, Triantafyllou NI, Kararizou E, Gatzonis SS, Fountoulakis KN, Siatouni A, et al. Depression and anxiety in epilepsy: the association with demographic and seizurerelated variables. Ann Gen Psychiatry. 2007; 6 (1):28.

35. Chen Q, Yan XX, Shang NX, Zhang GZ, Gao ZJ, Wang Y, et al. Zhonghua Er Ke Za Zhi. 2010; 48 (5): 346-500.

36. Carne RP, O'Brien TJ, Kilpatrick CJ, MacGregor LR, Hicks RJ, Murphy MA, et al. MRI-negative PET-positive temporal lobe epilepsy: a distinct surgically remediable syndrome. Brain 2004; 127: 2276-285.

37. Kanner AM. When did neurologists and psychiatrists stop talking to each other? Epilepsy Behav. 2003; 4: 597-601.

38. Kanner AM. Depression and Epilepsy: A New Perspective on Two Closely Related Disorders. Epilepsy Curr. 2006; 6(5): 141-146. 
Table 1: Socio-demographic characteristics of the patients with epilepsy

\begin{tabular}{lll}
\hline Variables & N & $(\%)$ \\
\hline Age (years) & & \\
$=25$ & 21 & $(33.3)$ \\
$>25-40$ & 24 & $(38.1)$ \\
$>40$ & 18 & $(28.6)$
\end{tabular}

\section{Religion}

Christianity 19

Islam $44 \quad$ (69.8)

Educational level

No formal education 12

Primary education $\quad 16$

Secondary education $\quad 16$

Tertiary education 19

Occupational status

Employed 27

Unemployed 36

Marital status

Currently in a marriage 29

Never married $\quad 30$

Divorced 2

Widowed 2

Total number of patients $(\mathrm{N}=63)$ except where otherwise indicated 
Table 2: Some Psychosocial characteristics of the patients with epilepsy

\begin{tabular}{|c|c|c|}
\hline Variables & $\mathbf{N}$ & $(\%)$ \\
\hline \multicolumn{3}{|c|}{ Stigma because of illness } \\
\hline Yes & 21 & (33.3) \\
\hline No & 42 & $(66.7)$ \\
\hline \multicolumn{3}{|c|}{ Limitation in physical activity } \\
\hline Present & 33 & $(52.4)$ \\
\hline Absent & 30 & $(47.6)$ \\
\hline \multicolumn{3}{|c|}{ Limitation in occupational activity $(\mathrm{N}=62)$} \\
\hline Present & 29 & $(46.8)$ \\
\hline Absent & 33 & $(53.2)$ \\
\hline \multicolumn{3}{|c|}{ Financial difficulties } \\
\hline Present & 26 & $(41.3)$ \\
\hline Absent & 37 & $(58.7)$ \\
\hline \multicolumn{3}{|c|}{ Perceived social support } \\
\hline Adequate & 43 & $(68.3)$ \\
\hline Inadequate & 20 & $(31.7)$ \\
\hline \multicolumn{3}{|c|}{ Perceived level of adjustment } \\
\hline Well adjusted & 41 & $(65.1)$ \\
\hline Not well adjusted & 22 & $(34.9)$ \\
\hline \multicolumn{3}{|c|}{ History of birth difficulties ( $N=28$ ) } \\
\hline Present & 13 & $(46.4)$ \\
\hline Absent & 25 & $(53.6)$ \\
\hline \multicolumn{3}{|c|}{ Childhood medical problems $(\mathrm{N}=41)$} \\
\hline Present & 14 & $(34.2)$ \\
\hline Absent & 27 & $(65.8)$ \\
\hline
\end{tabular}


Table 3: Factors associated with psychiatric diagnoses in Patients with epilepsy

\begin{tabular}{|c|c|c|c|c|c|}
\hline Variables & $\begin{array}{l}\text { Cases } \\
n=18\end{array}$ & $\begin{array}{l}\text { Non-Cases } \\
\mathrm{n}=\mathbf{4 5}\end{array}$ & $\begin{array}{l}\text { Odd } \\
\text { ratio }\end{array}$ & $\begin{array}{l}95 \% \\
\text { Confidence } \\
\text { interval }\end{array}$ & $P$ value \\
\hline Age in years $(N=63)$ & & & 0.25 & $0.06-0.94$ & 0.038 \\
\hline$\leq 40$ & 9 & 36 & & & \\
\hline$>40$ & 9 & 9 & & & \\
\hline Gender $(\mathrm{N}=63)$ & & & 0.17 & $0.04-0.67$ & 0.007 \\
\hline Male & 5 & 31 & & & \\
\hline Female & 13 & 14 & & & \\
\hline $\mathrm{EEG}(\mathrm{N}=28)$ & & & 0.13 & $0.01-1.06$ & 0.042 \\
\hline Normal & 2 & 13 & & & \\
\hline Abnormal & 7 & 6 & & & \\
\hline Type of seizure $(\mathrm{N}=54)$ & & & 6.29 & $1.39-30.22$ & 0.012 \\
\hline Partial & 8 & 6 & & & \\
\hline Generalized & 7 & 33 & & & \\
\hline Presence of stigma $(\mathrm{N}=63)$ & & & 0.74 & $0.18-2.95$ & 0.857 \\
\hline Yes & 8 & 13 & & & \\
\hline No & 10 & 32 & & & \\
\hline Physical activity limitation $(\mathrm{N}=62)$ & & & 4.79 & $1.2-20.68$ & 0.023 \\
\hline Present & 14 & 19 & & & \\
\hline Absent & 4 & 26 & & & \\
\hline Occupational activity limitation $(\mathrm{N}=62)$ & & & 6.77 & $1.66-29.00$ & 0.004 \\
\hline Present & 14 & 15 & & & \\
\hline Absent & 4 & 29 & & & \\
\hline Financial difficulties $(\mathrm{N}=63)$ & & & 4.43 & $1.21-16.87$ & 0.021 \\
\hline Present & 12 & 14 & & & \\
\hline Absent & 6 & 31 & & & \\
\hline
\end{tabular}


Table 4: Terminal log odds and Exp (B) in the multiple logistic regression equation of risk factors for psychiatric morbidity in patients with epilepsy

\begin{tabular}{|c|c|c|c|c|}
\hline Variables & $\begin{array}{l}\text { B } \\
\text { (Log odds) }\end{array}$ & $\begin{array}{l}\operatorname{Exp}(\mathbf{B}) \\
\text { (Odd ratio) }\end{array}$ & $\begin{array}{l}95 \% \\
\text { Confidence } \\
\text { interval }\end{array}$ & $\begin{array}{l}\text { Level of } \\
\text { significance }\end{array}$ \\
\hline $\begin{array}{l}\text { Gender } \\
\text { Male } \\
\text { Female }\end{array}$ & 2.653 & 0.070 & $0.009-0.523$ & 0.010 \\
\hline $\begin{array}{l}\text { Epilepsy type } \\
\text { Partial } \\
\text { Generalized }\end{array}$ & 2.028 & 7.595 & $1.239-46.576$ & 0.028 \\
\hline $\begin{array}{l}\text { Occupational limitation } \\
\text { Present } \\
\text { Absent }\end{array}$ & 2.309 & 10. 069 & $1.468-69.047$ & 0.065 \\
\hline $\begin{array}{l}\text { Financial difficulties } \\
\text { Present } \\
\text { Absent }\end{array}$ & 1.754 & 5.775 & $0.900-37.071$ & 0.093 \\
\hline
\end{tabular}

Table 5: Number of psychosocial problems and the average GHQ scores of patients with epilepsy

\begin{tabular}{llll}
\hline $\begin{array}{l}\text { Number of } \\
\text { psychosocial } \\
\text { problems }\end{array}$ & $\begin{array}{l}\text { Number of patients } \\
\text { with psychosocial } \\
\text { problems (N=63) }\end{array}$ & $\begin{array}{l}\text { Total GHQ } \\
\text { scores }\end{array}$ & $\begin{array}{l}\text { Average GHQ } \\
\text { Scores of } \\
\text { patients }\end{array}$ \\
\hline 1 & 6 & 2 & 0.33 \\
2 & 11 & 7 & 0.64 \\
3 & 15 & 11 & 0.73 \\
4 & 10 & 8 & 0.80 \\
5 & 9 & 18 & 2.00 \\
6 & 10 & 39 & 3.90 \\
7 & 2 & 8 & 4.00 \\
\hline
\end{tabular}




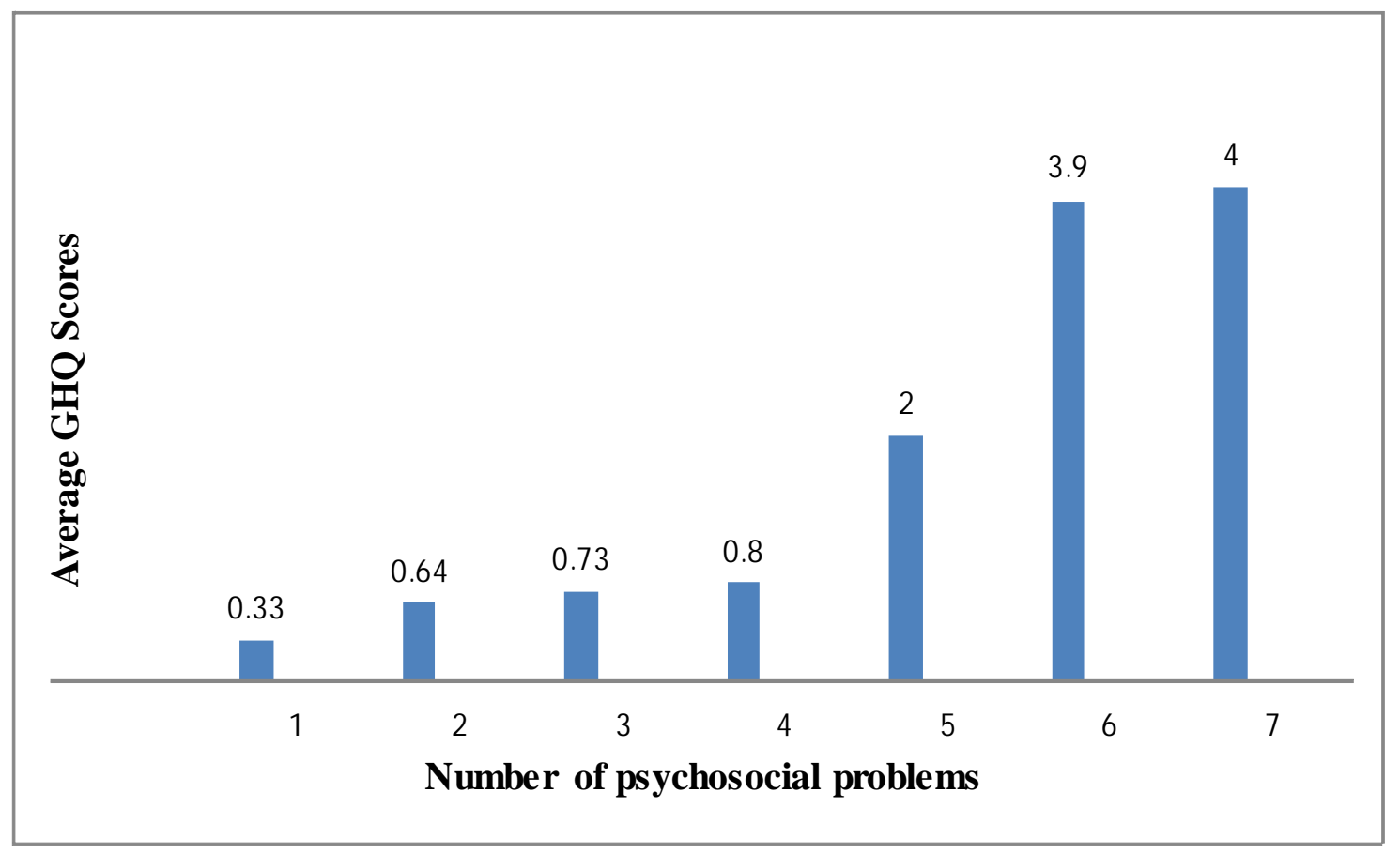

Figure 1. Number of psychosocial problems and average GHQ scores of patients with epilepsy 